\title{
A measurement of the lunar semidiurnal tide at Wuhan $\left(30^{\circ} 40^{\prime} \mathrm{N}, 114^{\circ} 30^{\prime} \mathrm{E}\right)$
}

\author{
X. J. Niu ${ }^{1,2}$, J. G. Xiong ${ }^{1}$, W. X. Wan ${ }^{1}$, B. Q. Ning ${ }^{1}$, and L. B. Liu ${ }^{1}$ \\ ${ }^{1}$ Institute of Geology and Geophysics, Chinese Academy of Sciences, Beijing, China \\ ${ }^{2}$ School of Physics \& Information Engineering, Jianghan University, Wuhan, China
}

(Received April 30, 2006; Revised July 14, 2007; Accepted July 20, 2007; Online published September 28, 2007)

\begin{abstract}
Upper atmospheric winds have been measured at heights from 80 to $100 \mathrm{~km}$ over Wuhan $\left(30^{\circ} 40^{\prime} \mathrm{N}, 114^{\circ} 30^{\prime} \mathrm{E}\right)$, China with a meteor radar from 2002 to 2005. The variations of lunar semidiurnal tidal amplitudes and phases with both seasons and heights are studied in detail to reveal the properties of the lunar semidiurnal tide. It is shown that the lunar semidiurnal tide is stronger in January than other months, and its second peak appears near August. For most months the eastward maximum is $3 \pm 1$ lunar hours later than the northward maximum, as classical theory predicts for a northern hemisphere tide. The observed seasonal and height variations are also compared with the Global Scale Wave Model (GSWM). The phases do not agree well with those of the GSWM model. The maximum amplitude occurs in a different month in the model. There are about 5 lunar hours phase difference between the observed and the model at 90 and $96 \mathrm{~km}$ in eastward and northward components. A comparison of the lunar and solar semidiurnal tides is also shown in this paper. The behavior of these two tides in season is different, especially for the month of appearance of maximum amplitude.
\end{abstract}

Key words: Lunar tide, meteor radar, GSWM model.

\section{Introduction}

The dynamics of the MLT region (mesosphere and lower thermosphere region) are dominated by waves and tides most of which propagate to this region from sources at lower heights. These waves interact strongly with each other and with the mean flow, driving the mean flow to states far removed from those predicted by considerations of pure radiative equilibrium alone. Understanding the tides and waves of the MLT region is thus crucial in understanding the entire circulation of this part of the atmosphere and how it couples to regions above and below. In spite of their small amplitude, the lunar atmosphere tides are of considerable interest for many reasons. Lunar tides are generated mainly in the lower, denser regions of the atmosphere as a result of the Moon's gravitational force. Mathematically speaking, the formulation of the atmospheric lunar tides is analogous to finding the atmospheric response to an oscillating lower boundary. They propagate upward to the upper atmosphere in the form of various tidal oscillation modes. Investigators of the upper atmosphere have long realized that there ate considerable tidal variations in ionospheric parameters with lunar period. The lunar tidal variation allows one to look at dynamical effects decoupled from the effects of ionizing radiation (Marvin, 1970). Early observations and theories of the lunar tide in the atmosphere have been summarized by Chapman and Lindzen (1970). In the MLT region, several of lunar tide observations have been reported (Stening et al., 1987; Stening and Vincent, 1989; Stening et al., 1990; Stening et al., 1994; Stening et al., 2003). Lu-

Copyright (c) The Society of Geomagnetism and Earth, Planetary and Space Sciences (SGEPSS); The Seismological Society of Japan; The Volcanological Society of Japan; The Geodetic Society of Japan; The Japanese Society for Planetary Sciences; TERRAPUB. nar tidal harmonics have also been detected in geomagnetic data (Stening, 1989). The lunar tide propagates up into the E region of the ionosphere where it generates electric currents by dynamo action. These lunar ionospheric current system and wind shears in the lunar atmospheric tide may affect the motions of the Es layer. The lunar E region dynamo also generates electrostatic fields and it is these fields, when transmitted along magnetic field lines to the $\mathrm{F}$ region, which give rise to the lunar periodicities in the $\mathrm{F}$ region ionization density and thus in the $\mathrm{F}$ region critical frequency (Stening, 1986). An oscillation signal at the lunar period has also been found in the parameters of the Es and F2 regions (Stening, 1999; Stening and Fejer, 2001).

Using the data at about 60 to $110 \mathrm{~km}$ height range observed by MF and meteor radars, Stening and his collaborators have studied the lunar tide over many stations such as Adelaide $\left(35^{\circ} \mathrm{S}, 138^{\circ} \mathrm{E}\right)$, Saskatoon $\left(52^{\circ} \mathrm{N}, 107^{\circ} \mathrm{E}\right)$ and Jakarta $\left(6.4^{\circ} \mathrm{S}, 106.7^{\circ} \mathrm{E}\right)$ (Stening et al., 1994; Stening et al., 2003). Based on the model of Forbes (Forbes, 1982), Vial and Forbes (1994) provided a comprehensive modal of the atmospheric $\mathrm{M}_{2}$ lunar tidal oscillations from the ground to the lower thermosphere. This model took account of the effects of earth, ocean and load tides. Hagan et al. (1995) developed a 2-dimensonal, linear numerical model (GSWM model) describing planetary waves and solar tides. Using the GSWM model of Hagan et al. (1995), Stening et al. (1997a) extended the numerical model of Vial and Forbes (1994) to greater heights. Longitudinal and latitudinal variations were derived from this model. The results of this GSWM model were compared with lunar tide observed at Christmas Island and Collm respectively (Stening et al., 1997b; Stening and Jacobi, 2001). When the best available models of lunar atmospheric tidal winds were incorpo- 
rated into the equivalent circuit method dynamo calculation to simulate the lunar component of the observed daily geomagnetic variation, the results produced fair good agreement with the GSWM with only a few exceptions (Stening et al., 2002). Recently, Stening et al. (2003) compared the results of lunar tidal winds in the upper atmosphere over Jakarta with the GSWM model. They reported that the GSWM model is good but there is a difference in phase of the eastward wind in southern winter.

The lunar tides at Christmas Island, Jakarta and Collm, which are at equatorial, low latitude and high mid-latitudes respectively, have been compared with the GSWM model by Stening and coworkers (see Stening et al., 1997b; Stening and Jacobi, 2001; Stening et al., 2003), they found the observed $\mathrm{M}_{2}$ lunar tides at these stations agreed well with those of the model. But in the low mid-latitude region, there are fewer observations and so there is less opportunity for comparison between the observations and the model. In February 2002, a meteor radar system was established at the low mid-latitude site, Wuhan $\left(30^{\circ} 40^{\prime} \mathrm{N}, 114^{\circ} 30^{\prime} \mathrm{E}\right.$ ) (Xiong et al., 2004). The observational data of this radar from February 2002 to December from 2005 give us good opportunity to study the lunar tides at a low mid-latitude site. For all possible lunar periods the most important with the largest amplitudes is the semidiurnal $\mathrm{M}_{2}$ (12.42 solar hours) tide (Chapman and Lindzen, 1970). In this work presented here, observations of the $\mathrm{M}_{2}$ lunar tide at Wuhan and comparison with the GSWM are reported. In Section 2, the data and the analysis method are introduced. The comparison of the observed $\mathrm{M}_{2}$ lunar tide with the results derived from the GSWM model, as well as with the solar semidiurnal tide $\left(\mathrm{S}_{2}, 12\right.$ solar hours) is shown in Section 3. The discussion and conclusion are given in Sections 4 and 5, respectively.

\section{Data Analysis}

The radar at Wuhan is an all-sky interferometric radar, with a peak power of $7.5 \mathrm{~kW}$, a duty cycle of $10 \%$ at a frequency of $38.7 \mathrm{MHz}$ and a range sampling resolution of 2 $\mathrm{km}$. Before 18 September, 2002, the radar's pulse repetition frequency was $500 \mathrm{~Hz}$, and then it was raised to $1980 \mathrm{~Hz}$. The radar's characteristics are almost identical to the Buckland park meteor radar in Australia and the SKiYMET radar in Canada (Hocking et al., 2001; Holdsworth et al., 2004). The parameters used for routine observations and method of the first analysis the data were described by Xiong et al. (2004). The average daily number of meteors recorded by the radar is about 2500-3000, and almost all meteor echoes appear in the altitude region from 70 to $110 \mathrm{~km}$ with the peak counts near $91 \mathrm{~km}$. In this study, we only calculate the winds in the $80-100 \mathrm{~km}$ altitude region where the number of meteor echoes is enough to evaluate winds.

The least-squares method and Chapman-Miller method are two classical methods which have been used to analyze the lunar atmosphere tide. In 1980, the least-squares method was originally introduced and compared with the method of Chapman-Miller by Malin and Schlapp (1980). Compared with the other lunar tidal analysis method, they found that the least-squares method has several advantages. As a conventional method of analysis, it is unique in not having a systematic bias in the error estimation (Schlapp et al., 1996). Another advantage is that the scattered missing data are not a problem because each hourly data point is treated separately in the method (Stening et al., 1997b). So this method is useful even if there are gaps in the data. The results of the least-squares method can be presented either in the frequency domain or in the time domain, this is one of the advantages of the method and other advantages also have been described carefully by Schlapp et al. (1996). The main drawback is that a somewhat large number of data points need to be included in each data set in order to get significant results (Stening and Jacobi, 2001). Based on these many advantages, we adopted this method in this paper. In our analysis, we firstly used the observation data with radial velocity less than $150 \mathrm{~m} / \mathrm{s}$ to gain the hourly wind velocities (Xiong et al., 2004). Then using these hourly values, we determined the lunar semidiurnal tide by the least-squares method.

The hourly zonal and meridional winds are assumed to have the form,

$$
y(t)=y_{0}+\sum_{i=1}^{2} A_{i} \sin \left(i t+\phi_{i}\right)+A_{l} \sin \left(2 \tau+\varphi_{l}\right) .
$$

Where (in radians) $t$ is the local solar time and $\tau$ is the local lunar time $(\tau=t+h-s, v=s-h$, here $h$ is the longitude of the mean sun and $s$ is the longitude of the mean moon, $v$ is the lunar age, $\phi_{i}$ and $\varphi$ are the phases of solar and lunar tides. In the analysis the lunar tide is derived by calculating the lunar age $v$ of each data point and the phase of the lunar tide presented as the lunar hour of maximum $\tau_{\max } . \tau_{\max }$ is related to the phase $\varphi$ (in degrees) by $\tau_{\max }=3-\varphi / 30$.). In Eq. (1), the first item is the mean term, the second item includes solar diurnal and semidiurnal tides and the last item is the lunar semidiurnal tide. The amplitudes of lunar atmospheric tides are often very small and difficult to determine in the presence of the ambient noise, so realistic error estimation is very important if one wishes to assess the significance and reliability of any lunar tidal determination. The least-squares method of Malin and Schlapp (1980) used a different method of error estimation from the conventional one in order to provide a more realistic estimation. Most methods often use the sum of the squares of the residuals from the variation obtained by synthesis from all the coefficients, but the Malin and Schlapp (1980) least-squares method proceeds by subdividing the data into a number of random subsets. Then the errors in the harmonic coefficients or the values for a time variation are estimated from the scatter among the determinations from the different subsets. Following then we assigned randomly the data to typically ten separate sets and then seven unknowns in (1) for each subset are obtained by the least-square method. The good estimates of the errors in these seven coefficients are obtained from the scatter in the results from the ten subsets.

\section{Results}

\section{1 $\mathrm{M}_{2}$ lunar tide}

The average seasonal variations of the amplitude and phase of the $\mathrm{M}_{2}$ lunar tide at $80-100 \mathrm{~km}$ height range are shown in Fig. 1. In this analysis data are taken from January 

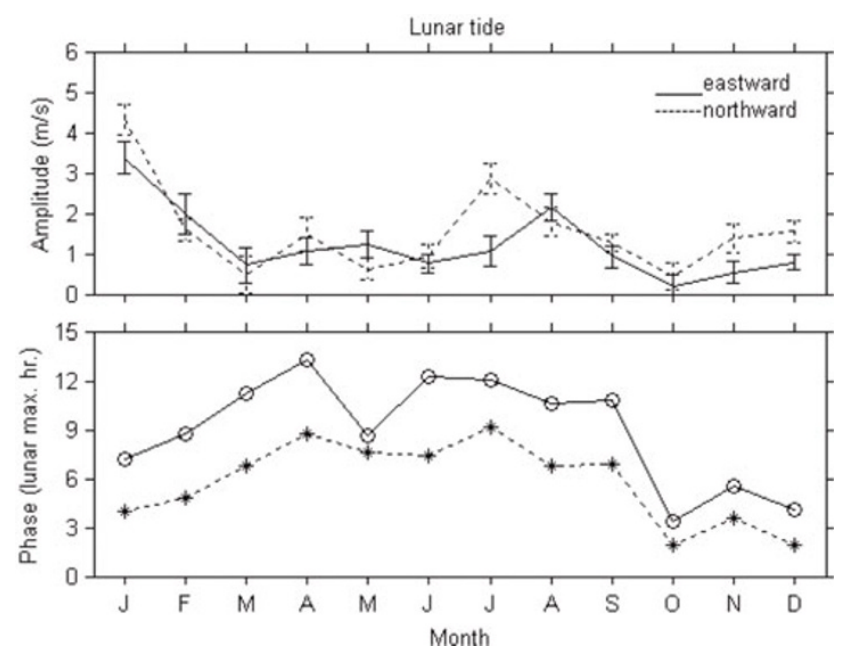

Fig. 1. Variation with season of the amplitude and phase of the $\mathrm{M}_{2}$ lunar tide. Data from 80-100 height range analyzed together from 2002 to 2005. The error bars represent \pm one standard deviation.

29, 2002 to December 23, 2005 at $80-100 \mathrm{~km}$ height range, except February 26 to April 22 in 2003 and February 10 to 17 in 2005 (during these time, the radar did not work). In order to improve our statistics, the data from the same month of different years at $80-100 \mathrm{~km}$ height range were analyzed together. But this will average out changes of the phase with height and the annual variations. In Fig. 1 we only give the seasonal variation of $\mathrm{M}_{2}$ lunar tide. Later we give the phase variation with height and year. The error bars indicate one standard deviation. If the amplitude is less than one standard error then its associated phase is unreliable. If the amplitude is greater than 2 standard deviations, then the tide is well determined and if the amplitude is between one and two standard errors, its associated phase is only moderately (68\% 95\%) reliable (Stening et al., 1997b). These considerations are taken into account in the following figures. Figure 1 shows that the amplitudes of eastward and northward components are generally close and that a clear seasonal variation is apparent in which largest amplitudes are observed in January and July-August. Using 6 years of data from Saskatoon, Stening et al. (1987) also found the largest amplitudes of the $\mathrm{M}_{2}$ lunar tide occur in January-February with a smaller maximum in summer. At two stations of Eaton $\left(52.6^{\circ} \mathrm{N}, 2.19^{\circ} \mathrm{W}\right)$ and Esrange $\left(67.9^{\circ} \mathrm{N}, 21.1^{\circ} \mathrm{E}\right)$, Sandford et al. (2006) found the lunar tide has maximum amplitudes in winter (January-February) with a second autumnal (September-October) maximum. At Wuhan there is a second northward amplitude peak in July and an eastward peak in August. The second peak of the $\mathrm{M}_{2}$ lunar tide at Wuhan appears about one to two months earlier than that at Eaton and Esrange-both sites are at higher latitudes than Wuhan. Some studies show that larger amplitudes of the lunar tide occur in the two equinoctial months (Stening, 1989; Stening et al., 1990; Schlapp and Harris, 1993; Stening and Jacobi, 2001). The observations at Wuhan do not agree with this. The phases of the lunar tide at Wuhan also have significant seasonal variations for both components. The seasonal phase progression of the eastward component is quite similar to the northward. The
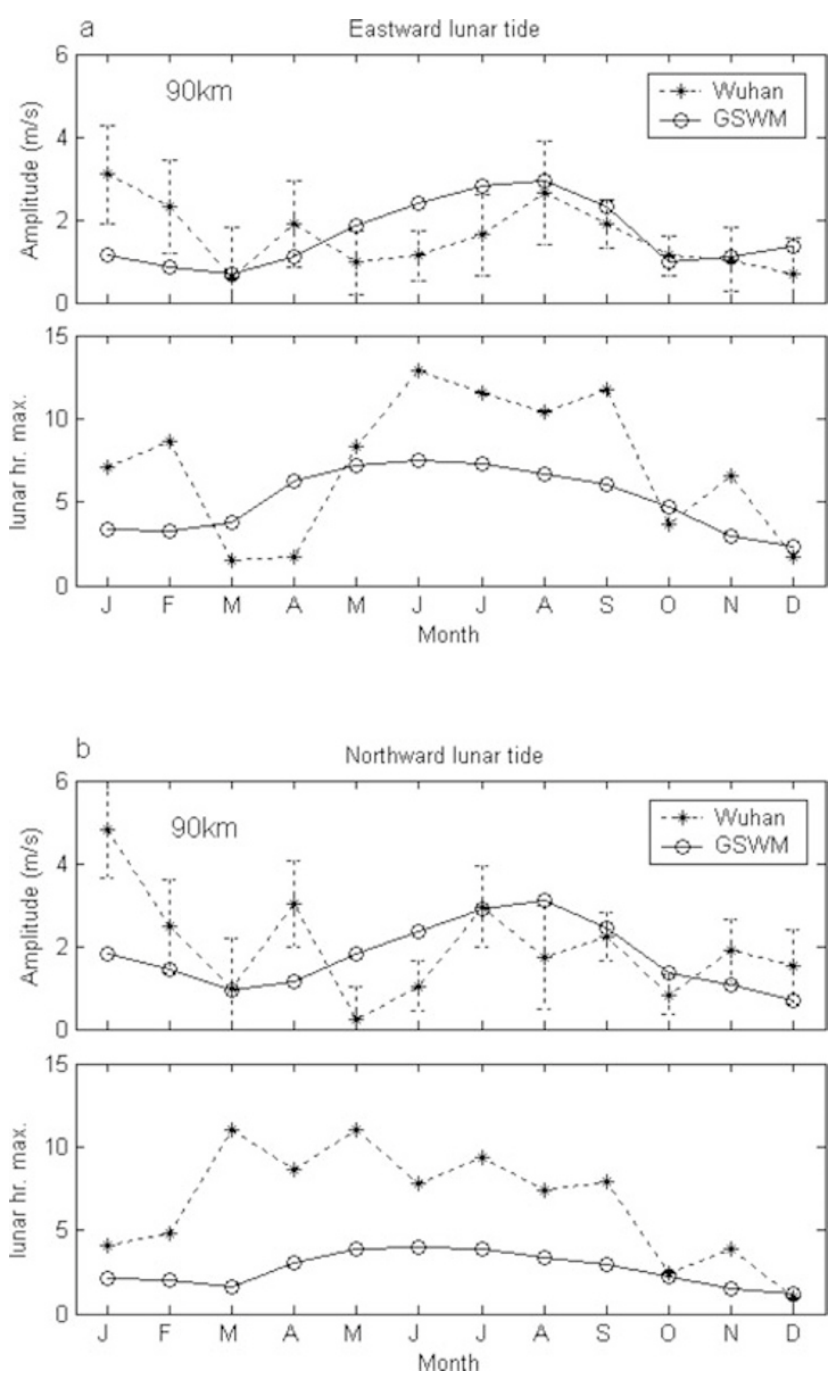

Fig. 2. Variation with season of the amplitude and phase of the $\mathbf{M}_{2}$ lunar tide in the winds as compared with the GSWM at $90 \mathrm{~km}$. (a) eastward component and (b) northward component.

expected phase difference about 3 hours between the northward and eastward components is seen in most months with the eastward phase lagging. During October to December and in May, the phase difference decreases to about one hour. This is in accordance with the results of Stening et al. (2003). They presented the eastward phase later than the northward one in the Northern Hemisphere and there is $3 \pm 1$ hours phase difference between them. With both the northward and eastward components, there is a rapid phase jumping between September-October and the phases during October to December precede other months.

\subsection{Comparing with the GSWM model}

In order to compare the measurements with the GSWM model, the data at a selected height during January 29, 2002 to December 23, 2005 are put together to get the results using the least-square method as before. For example, all data in May of 2002, 2003, 2004 and 2005 are treated as a dataset for May. So we can evaluate the averaged lunar tide of those years for every height between 80 and $100 \mathrm{~km}$. The modeled and observed $\mathrm{M}_{2}$ tide is compared in Fig. 2 and Fig. 3 for the 90 and $96 \mathrm{~km}$ heights, respectively. At $90 \mathrm{~km}$, the observed maximum in amplitudes of $\mathrm{M}_{2}$ lunar tide for 

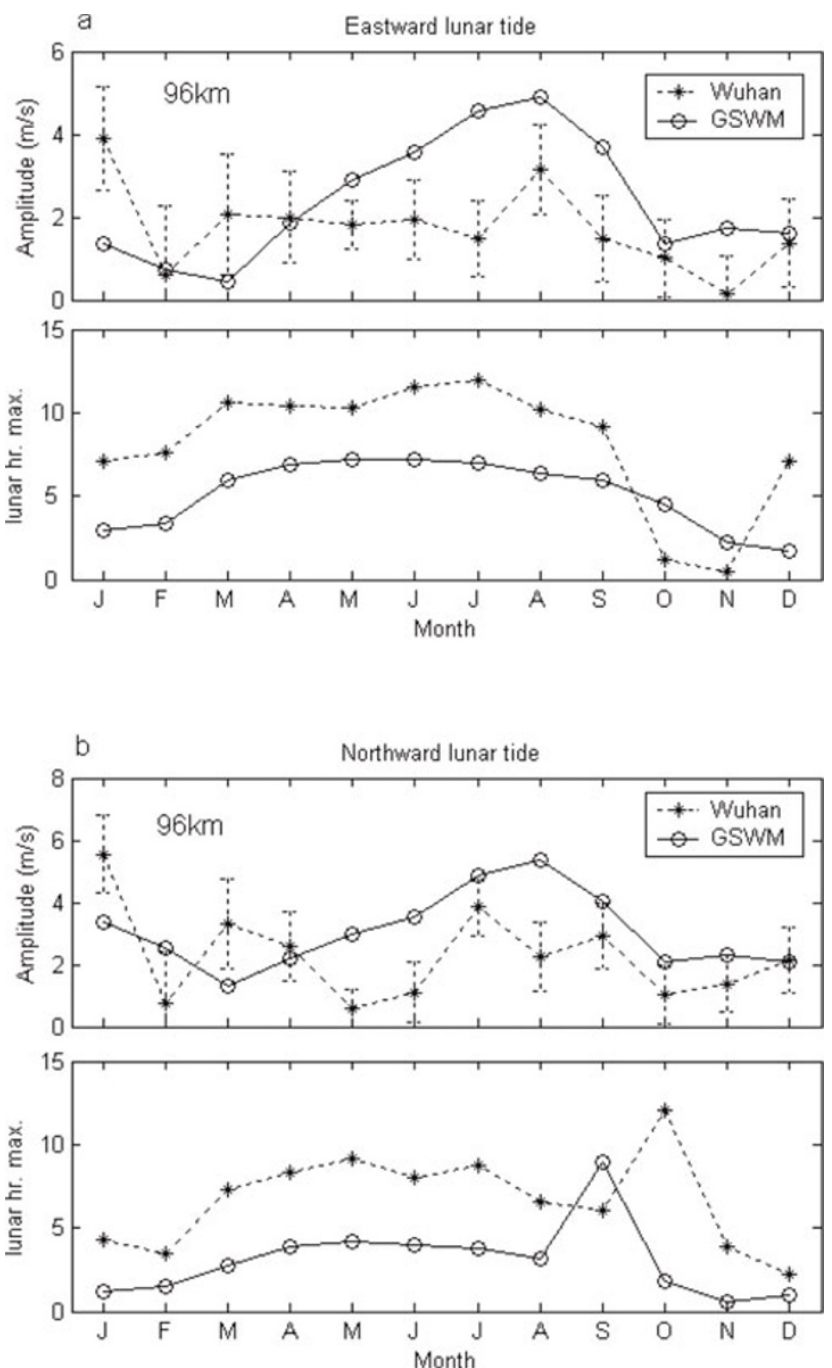

Fig. 3. Same as Fig. 2 but for the data at $96 \mathrm{~km}$.

eastward and northward components occurs in January but in August for the model. However, the observed eastward amplitude is quite strong during August-September although it is not the maximum amplitude. There are about 5 lunar hours phase difference between the observed and the model eastward tidal phases, except in March, May, October and December. In March, May and December, the corresponding amplitudes are less than one standard error, so the phases in these months are unreliable. For the northward wind, the phases agree with the model to about $3 \pm 1$ hours from October to February. The other months, the phase difference is larger. The model phase of eastward wind is earlier in winter than other seasons. From March to September, the eastward phases of the model have a mean value about 7 hours. And in other months, the average phase value is about 3 hours. The northward phase of the model has no significant variation with season. The mean value is about 3 lunar hours. But the phase of the observed northward wind varies with season, especially in winter.

At $96 \mathrm{~km}$, the amplitude behaves in a very similar fashion with $90 \mathrm{~km}$. Again a maximum amplitude appears in January of the observed results but not in the model. About 5 lunar hours phase difference between the observed and
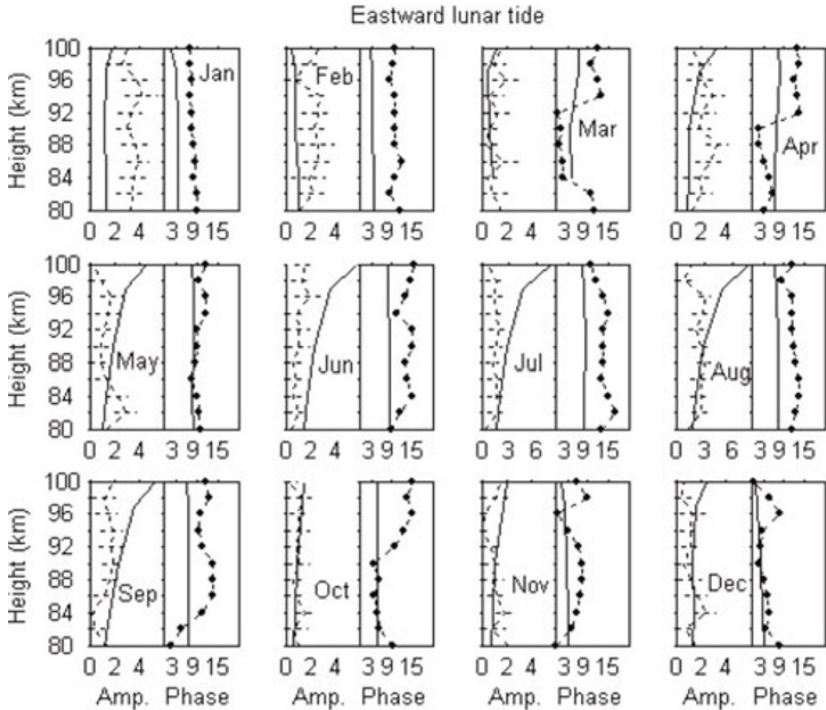

Fig. 4. Height profiles of the amplitudes and phases of the eastward $\mathrm{M}_{2}$ lunar tide in the winds as compared with the GSWM. Thick line is for the results of model and thin line for the observed. The error bars represent \pm one standard deviation.
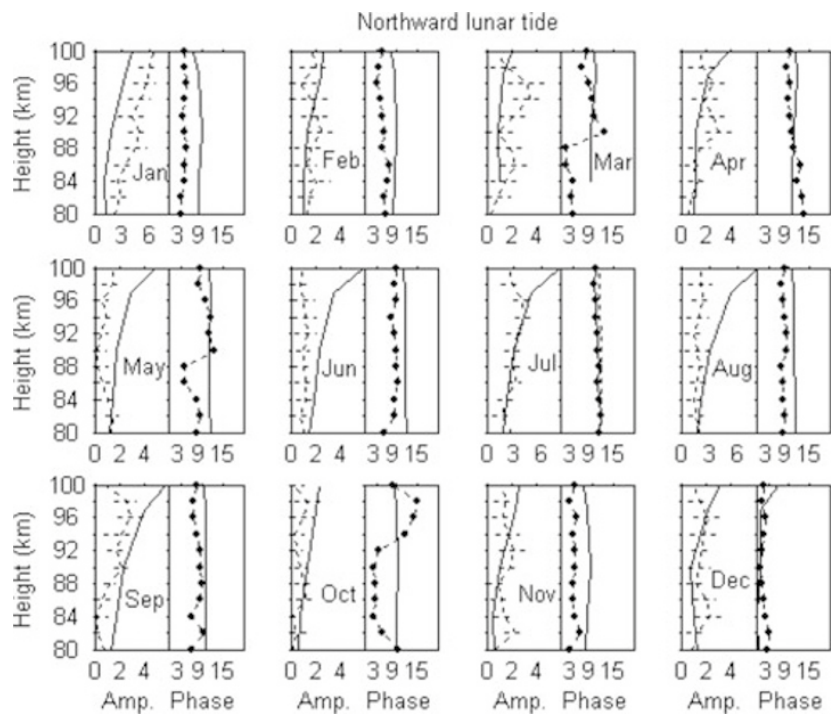

Fig. 5. Same as Fig. 4 but for the northward component.

the model phase in eastward component still occurs, except in October and November. But the amplitude for November is almost zero. So the corresponding phase value would have almost no meaning. The difference of the northward phases from the model is smaller in winter. The amplitudes of northward component in February, May, June and October is less than one standard error, so the northward phases in these months are unreliable. Although the trend of the observed phase with season is similar with the model, there is some difference in some months.

In Fig. 4 and Fig. 5, we show the height profiles of the eastward and northward $\mathrm{M}_{2}$ lunar tide from January to December, respectively. For the eastward component, in January, February and below $96 \mathrm{~km}$ in April, the observed amplitudes of $\mathrm{M}_{2}$ lunar tide are stronger than the model amplitudes. From October to December, March and below 

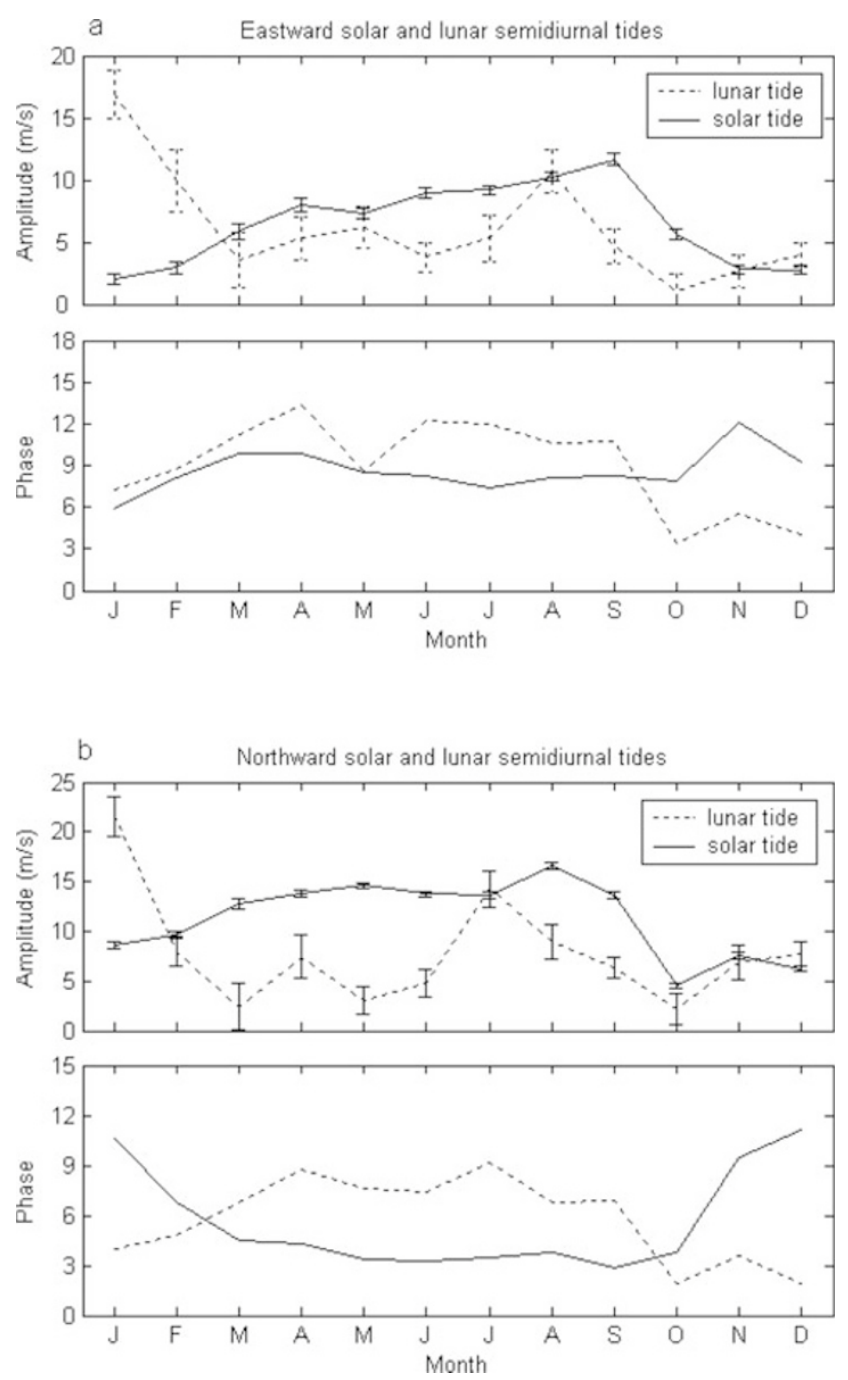

Fig. 6. Seasonal variations of the solar and lunar semidiurnal tides. Data included here are from 80 to $100 \mathrm{~km}$ and March, 2002 to December, 2005. The amplitude of the lunar tide has been multiplied by 5 . The error bars represent \pm one standard deviation. (a) eastward component and (b) northward component.

$90 \mathrm{~km}$ in August, the observed amplitude is very close to that of the model. In other months, the observed $\mathrm{M}_{2}$ lunar tide is weaker than the model calculated. Especially above $96 \mathrm{~km}$, the model predicts much larger amplitude of the $\mathrm{M}_{2}$ lunar tide from May to September. Over Collm $\left(52^{\circ} \mathrm{N}\right.$, $15^{\circ} \mathrm{E}$ ), at these greater heights the model amplitudes also are very much larger than those observed (Stening and Jacobi, 2001). In most months, the phase progressions of the observed and the model are similar, but there is a difference in value between them. In May, December and below $90 \mathrm{~km}$ in October, the model and observed phases agree quite well. The comparison of the northward amplitudes (Fig. 5) with those of the model is broadly similar to that for the eastward wind. The difference of amplitude between the observed and the model is small. In some months, phases of observations and model agree well, especially in winter.

\subsection{Comparing with the solar semidiurnal tide}

The period of solar semidiurnal tide is close to that of the $\mathrm{M}_{2}$ lunar tide. From Eq. (1), in the same analysis the phase and amplitude variations of the solar semidiurnal tide were
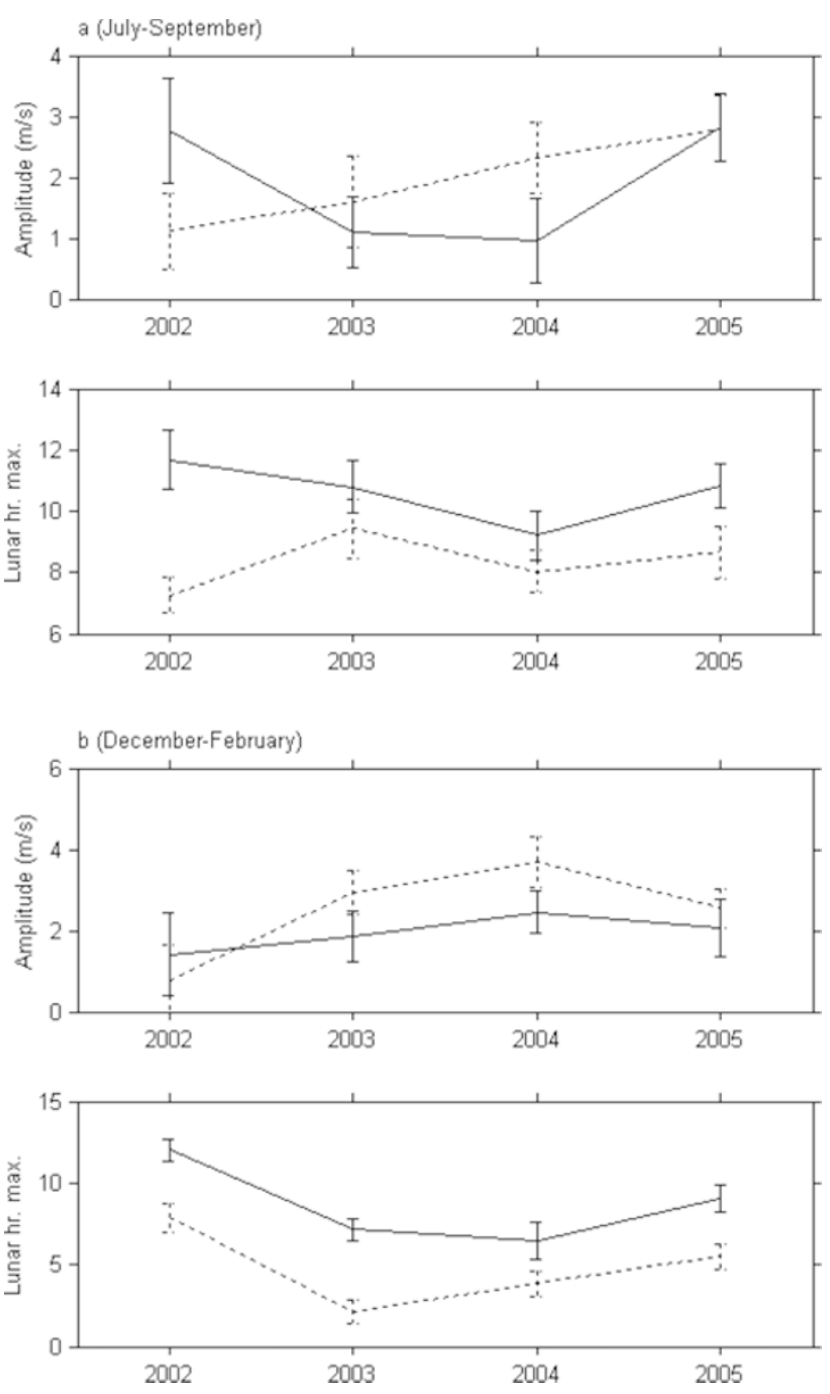

Fig. 7. Variation with year of the amplitude and phase of the $\mathrm{M}_{2}$ lunar tide using data conclude height range $88-92 \mathrm{~km}$. (a) is July-September and (b) is November-January. Solid line is eastward wind and dashed line is northward one.

also obtained. The results are plotted alongside those of the lunar tide in Fig. 6. To highlight the difference, the amplitude of the $\mathrm{M}_{2}$ lunar tide has been multiplied by 5 . For the eastward components, the solar semidiurnal tide does not show a maximum in January as was found for the lunar tide. The amplitude of solar tide increases from March to September and becomes weak in winter. A main feature of the northward solar semidiurnal tide is its drop in amplitude in October, which is accompanied by a phase change. The solar semidiurnal tide strong in autumn is consistent with the observations (Tsuda and Kato, 1988; Vincent et al., 1988). Although the frequencies and mode structures of the solar and lunar semidiurnal tides are similar, their behaviors are not similar. The lunar tide, generated largely in the troposphere, has to propagate before a larger expanse of intervening atmosphere before reaching the heights discussed in this paper. The solar tides are forced by absorption of sunlight at several different altitudes, ranging from the troposphere (absorption by water) to the lower mesosphere (absorption by ozone). 


\subsection{Year-to-year variations}

Examination of year-to-year changes sometimes shows consistent phases from year to year and sometimes different phase "states" appear in different years in Jakarta (Stening et al., 2003). In Fig. 7, we give the amplitude and phase for July-September and December-February with only a single year's data at $88-92 \mathrm{~km}$ height range included in each point. (a) is in July-September and (b) is in December-February. During July-September, both phase and amplitude of the lunar tide vary in different years, though the northward phase has little change from 2003 to 2005 and the phase of the eastward wind stays at $11 \pm 2$ lunar hr. During December-February, the amplitude changes are small but the phase can almost reverse from one year to the next.

\section{Discussion}

The lunar tide at Christmas Island was found to agree reasonably well with the GSWM, the experimental phases have errors between one and two lunar hours (Stening et al., 1997b). Over Jakarta the northward wind phases agree with the GSWM model within an error of 1 hour except in March-April-May, and the eastward phase agrees within an error of 1 hour in the summer months. But from June to September, there are about 6 lunar hours phase difference between the observed and the model in eastward component (Stening et al., 2003). The model predicted much larger amplitudes of the lunar tide above $100 \mathrm{~km}$ than the observation at Collm (Stening and Jacobi, 2001). The observation at Wuhan shows that the seasonal variation of phase progression agrees with the GSWM at 90 and $96 \mathrm{~km}$ in most months. But in some months there are differences between the observed and the model results. The variation of lunar tide with height at Wuhan does not agree with the model in some months, especially above $96 \mathrm{~km}$. In the foregoing analyses, we have selected all the data from nearly four years. A larger number of data may improve our statistical significance but may average out changes of phase with height and from year to year. In the same months of different years, the lunar tide may be different.

It is known that changes in background winds and temperature gradients are likely to affect the propagation of the lunar tide through the atmosphere (Lindzen and Hong, 1974; Aso et al., 1981). Changes in the background winds in the stratosphere and mesosphere can have profound effects on the structure of the lunar tide in the upper atmosphere, while changes in the temperature variation with latitude are less important (Stening et al., 1997a). The amplitude and height dependence of the background zonal wind have a significant influence on lunar tidal behavior (Stening et al., 2003). In different years, there are different underlying atmospheric conditions prevailing. So in the same month at a given height, the prevailing winds maybe different in different years. A year-to-year variation of the lunar tide has been found in Jakarta (Stening et al., 1994; Stening et al., 2003). The year-to-year variation of the background winds may be an indirect reason for the difference between the observed and model results.

At Wuhan, the maximum amplitude of lunar and solar semidiurnal tides appears in a different month. And in the same month, the maximum values appear at different heights. At the same height, the behavior of these two tides is also different. These facts probably may be explained by their different excitation heights. From the troposphere to the lower mesosphere, the solar tides are mainly forced by absorption of sunlight at different altitudes. The lunar tide is generated mainly in the troposphere. It propagates through a larger expanse of intervening atmosphere before reaching the mesopause. Moreover, changes in the distributions of winds and temperature in the stratosphere will also affect the lunar and solar tides by different amounts.

Chapman and Lindzen (1970) have analyzed the upper atmospheric tides in terms of various "modes" which are solutions of Laplace's tidal equation. They found that the semidiurnal tide is dominated by the symmetric $(2,2)$ mode up to about $70 \mathrm{~km}$. Between 70 and $120 \mathrm{~km}$, "mode coupling" occurs due to influences of the background atmosphere and several higher order modes are also excited. Above $120 \mathrm{~km}$ the $(2,2)$ mode again becomes dominant. Generally, when the background winds do not change, the vertical wavelength of each tidal mode would be the same. If there is a change in the vertical wavelength, this may be a sign that the tidal mode is mixed or that the background winds have changed. Our observations from 80 to $100 \mathrm{~km}$ over Wuhan show the phase of the lunar tide has significant changes with height in some months. The vertical wavelength in different months and different heights shows great variability and is often shorter than predicted by theory. For example, in September (in Fig. 4) and in October (in Fig. 5), the observed phase obviously changes with height but the the model phase hardly varies with height. This may be due to the variable winds and the coupling modes. In fact, mode coupling has been predicted by theory and indeed observed at Adelaide and Saskatoon (Stening and Vincent, 1989). The presence of several modes at different heights and seasons leads to a complicated picture of the propagated tide. The results at Adelaide in summer showed wavelengths of $25 \mathrm{~km}$ occurred below $92 \mathrm{~km}$ and were evanescent above that, while in winter long wavelengths were found in the 78 to $90 \mathrm{~km}$ range with shorter $38 \mathrm{~km}$ wavelengths above that height. At Saskatoon, mode coupling also has been confirmed (Stening et al., 1987). The vertical wavelength is longest in summer, and the tide then resembles that predicted for a pure $(2,2)$ mode. In winter, vertical wavelengths range from 25 to $81 \mathrm{~km}$ in different years. And at Adelaide in 1986, the results differ from the results of 1983-1985 (Stening and Vincent, 1989). The different "mode coupling" in different years may be an important reason for the difference we find between the observed and the model results. Also Niu et al. have shown that symmetric and anti-symmetric modes were active in different seasons and the results are not in agreement with the results of Stening et al. (1994) in June and September (Niu et al., 2005). And there is year-to-year variability of lunar tide. Stening et al. reported finding a symmetric mode in 1985 and an antisymmetric mode in 1986 and 1987 during the period March to May (1994). This is also may be another important reason and also the reason of the difference of near latitudes. 


\section{Conclusions}

The $\mathrm{M}_{2}$ lunar tide in the mesosphere and lower thermosphere shows a seasonal variation at Wuhan. The amplitudes of both the eastward and northward lunar semidiurnal tides reach maxima in January, with a secondary peak during July-August. The phase of the $\mathrm{M}_{2}$ lunar tide also varies with season. The variation of both eastward and northward phases is similar in most months. Moreover, the theoretically predicted approximate 3 lunar hours phase difference between northward and eastward winds is present with the eastward phase later than the northward. The seasonal variation of the lunar semidiurnal tide is not the same as in the GSWM model. The January maximum amplitudes are not found in the model. There is around 5 lunar hours phase difference between the observed and the model in many months. The difference in phase between the observed and the model results is smaller in winter. The variation of the tide with height agrees well with the GSWM model in some months. But above $96 \mathrm{~km}$, the amplitude of the model is generally larger than that observed. In addition, year-toyear variation of the lunar tide is found at Wuhan. We have yet to unambiguously identify the basic causes of these year-to-year change.

Acknowledgments. The authors would like to thank Dr R. J. Stening for providing the GSWM model results. This research was supported by National Natural Science Foundation of China (40474060) and National Important Basic Research Project (G2000078407) and the KIP Pilot Project (kzcx3-sw-144) of Chinese Academy of Sciences.

\section{References}

Aso, T., T. Nonoyama, and S. Kato, Numerical simulation of semidiurnal atmospheric tides, J. Geophys. Res., 86, 11388-11400, 1981.

Chapman, S. and R. S. Lindzen, Atmospheric tides, D. Reidel, 1970.

Forbes, J. M., Atmospheric tides I, Model description and results for the solar diurnal component, J. Geophys. Res., 87, 5222-5240, 1982.

Hagan, M. E., J. M. Forbes, and F. Vial, On modeling migrating solar tides, Geophys. Res. Lett., 22, 863-896, 1995.

Hocking, W. K., B. Fuller, and B. Vandepeer, Real-time determination of meteor related parameters utilizing modern digital technology, J. Atmos. Terr. Phys., 63, 155-169, 2001.

Holdsworth, A. David, I. M. Reid, and M. A. Cervera, Buckland Park all-sky interfero-metric meteor radar, Radio Sci., 39, RS5009, doi:10. 1029/2003RS003014, 2004.

Lindzen, R. S. and S. S. Hong, Effects of mean winds and horizontal temperature gradients on solar and lunar semidiurnal tides in the atmosphere, J. Atmos. Sci., 31, 1421-1466, 1974.

Malin, S. R. C. and D. M. Schlapp, Geomagnetic lunar analysis by leastsquares, Geophys. J. R. astr. Soc., 60, 409-418, 1980.

Marvin, A. G., An investigation of the lunar semidiurnal tide in the atmosphere, J. Atmos. Sci., 27, 202-218, 1970.

Niu, X. J., J. G. Xiong, W. X. Wan, B. Q. Ning, L. B. Liu, R. A. Vincent, and R. M. Reid, Lunar tidal winds in the mesosphere over Wuhan and
Adelaide, Adv. Space Res., 36, 2218-2222, 2005.

Sandford, D. J., H. G. Muller, and N. J. Mitchell, Observations of lunar tides in the mesosphere and lower thermosphere at Arctic and middle latitudes, Atmos. Chem. Phys. Discuss., 6, 4643-4672, 2006.

Schlapp, D. M. and T. J. Harris, Lunar tidal analysis of $6 \mathrm{yr}$ of mesospheric wind data at Adelaide, J. Atmos. Terr. Phys., 55, 1629-1635, 1993.

Schlapp, D. M., R. J. Stening, J. M. Forbes, A. H. Manson, C. E. Meek, and R. A. Vincent, $\mathrm{N}_{2}$ and $\mathrm{M}_{2}$ lunar tides: Atmospheric resonance revisited, Ann. Geophys., 14, 826-836, 1996.

Shun Handa, The lunar tide of the ionospheric F2-region in Japan, $J$. Atmos. Terr. Phys., 40, 973-976, 1978.

Stening, R. J., Lunar effects in the region of the ionosphere, J. Geophys. Res., 91, 4581-4584, 1986.

Stening, R. J., A diurnal modulation of the lunar tide in the upper atmosphere, Geophys. Res. Lerr., 16, 307-310, 1989.

Stening, R. J., The lunar tide in sporadic E, Ann. Geophys., 17, 1344-1351, 1999.

Stening, R. J. and B. G. Fejer, Lunar tide in the equatorial F region vertical ion drift velocity, J. Geophys. Res., 106(A1), 221-226, 2001.

Stening, R. J. and C. Jacobi, Lunar tidal winds in the upper atmosphere over Collm, Ann. Geophysicate., 18, 1645-1650, 2001.

Stening, R. J. and R. A. Vincent, A measurement of lunar tides in the Mesosphere at Adelaide, South Australia, J. Geophys. Res., 94, 1012110129, 1989.

Stening, R. J., C. E. Meek, and A. H. Manson, Lunar tidal winds measured in the upper atmosphere $(78-105 \mathrm{~km})$ at Saskatoon, Canada, J. Atmos. Sci., 44, 1143-1151, 1987.

Stening, R. J., S. K. Avery, and D. Tetenbaum, Observations of lunar tides in upper atmosphere winds at Poker Flat, Alaska, J. Atmos. Terr. Phys., 52, 715-721, 1990.

Stening, R. J., A. H. Manson, C. E. Meek, and R. A. Vincent, Lunar tidal winds at Adelaide and Saskatoon at 80 to 100 km heights: 1985-1990, J. Geophys. Res., 99, 13273-13280, 1994.

Stening, R. J., J. M. Forbes, M. E. Hagan, and A. D. Richmond, Experiments with a lunar atmospheric tidal model, J. Geophys. Res., 102, 13465-13471, 1997a.

Stening, R. J., D. M. Schlapp, and R. A. Vincent, Lunar tides in the mesosphere over Christmas Island $\left(2^{\circ} \mathrm{N}, 203^{\circ} \mathrm{E}\right)$, J. Geophys. Res., 102, D22, 26239-26245, 1997b.

Stening, R. J., A. D. Richmond, and R. G. Roble, Lunar tides in the Thermosphere-Ionosphere-Electr-odyna-Mics General Circulation Model, J. Geophys. Res., 104, 1-13, 1999.

Stening, R. J., C. Carmody, and J. Du, Simulating the lunar geomagnetic variations, J. Geophys. Res., 107(A7), 1125-1135, 2002.

Stening, R. J., T. Tsuda, and T. Nakamura, Lunar tidal winds in the upper atmosphere over Jakarta, J. Geophys. Res., 108, 1192-1199, 2003.

Tsuda, T. and S. Kato, Characteristics of semidiurnal tides observed by Kyoto meteor radar and Saskatoon Medium-Frequency radar, J. Geophys. Res., 93, 7027-7036, 1988.

Vial, F. and J. M. Forbes, Monthly simulations of the lunar Semi-diurnal tide, J. Atmos. Terr. Phys., 56, 1591-1607, 1994.

Vincent, R. A., T. Tsuda, and S. Kato, A comparative study of mesospheric solar tides observed at Adelaide and Kyoto, J. Geophys. Res., 93, 699708, 1988.

Xiong, J. G., W. Wan, B. Ning, and L. Liu, First results of the tidal structure in the MLT revealed by Wuhan Meteor Radar $\left(30^{\circ} 40^{\prime} \mathrm{N}, 114^{\circ} 30^{\prime} \mathrm{E}\right), J$. Atmos. Terr. Phys., 66, 675-682, 2004.

X. J. Niu (e-mail: niuxj@mail.iggcas.ac.cn), J. G. Xiong, W. X. Wan, B. Q. Ning, and L. B. Liu 